\title{
Perineal Groove: A Rare and Benign Anorectal Malformation
}

\author{
Ramar $\mathbf{P}^{1}$, Shringi $\mathbf{S}^{2}$
}

\section{Introduction}

A female neonate born at term, to 30 year old mother, with no antenatal risk factors or teratogenic exposure. On examination birth weight was $3 \mathrm{kgs}$, baby had moist, reddish mucosal groove extending from fourchette to anal verge. External genitalia were phenotypic female. No palpable mass in inguinal region or per abdomen. No dysmorphic features. Other systems were normal. Baby passed meconium and urine through normal orifices within first 24 hours.

\section{Discussion}

Anorectal malformations are spectrum of disorders involving urogenital tract, rectum and distal anus. They occur in approximately 1 in every 4000 live births ${ }^{1}$. Perineal groove is one of the rare benign congenital malformations of fusion of median perineal raphe, according to International proposed classification of, Anorectal malformations ${ }^{2}$. First reported by Stephens in 1968, with three major features (i) A moist perineal cleft between the posterior fourchette and the anus, (ii) A normally developed vagina and urethra, (iii) Hypertrophy of the labial tails that surround the cleft $^{3}$. There is a paucity of literature, for the incidence and cause of this anomaly. The proposed pathogenesis are failure of fusion of median raphe and embryological remnant of urorectal septum ${ }^{4,5}$. Initially described as a benign anomaly exclusive for female babies, association with hypospadiasis and renal anomalies in male babies

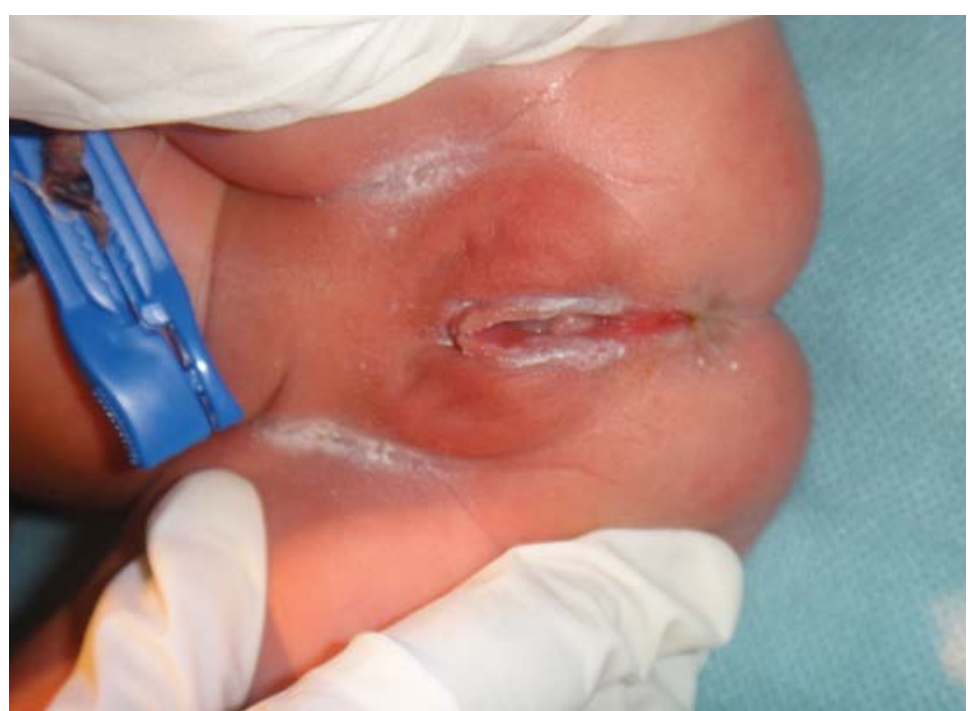

Fig 1: Showing perianal grove
1Dr. Praveen Ramar, MBBS, MD, Graded Specialist Dept of Paediatrics, ${ }^{2}$ Dr. Sandipan Shringi, MBBS. Both from 92 Base Hospital, C/O 56 APO, India.

Address for correspondence:

Dr. R Praveen

E-mail: praveen.army@gmail.com

\section{How to cite}

Ramar P, Shringi S. Perineal Groove: A Rare and Benign Anorectal Malformation. J Nepal Paediatr Soc 2015;35(1):94-95.

doi: http://dx.doi.org/10.3126/jnps.v35i1.10131

This work is licensed under a Creative Commons Attribution 3.0 License.

cc) $(7)$

are also documented ${ }^{6}$. Complications are persistent mucous discharge, recurrent UTI and constipation. Surgical therapy offered like excision, glue and suturing are done for cosmetic reasons.

\section{References}

1. Michael DK, Robert PT. Surgical conditions of the Anus, rectum and colon. In: Nelson text book of Pediatrics $18^{\text {th }}$ edn, Kleigman, Behrman, Jenson, Stanton eds. Philadelphia:WB Saunders, 2007;1635-1640.

2. Holschneider A, Hutson J, Pena A, et al. Preliminary report on the International Conference for the Development of Standards for the Treatment of Anorectal malformations. J Pediatr Surg 2005;40(10):1521-526 . 
3. Stephens FD. The female anus, perineum and vestibule. Embryogenesis and deformities. Aust $N$ Z J Obstet Gynaecol 1968;8:55-73.

4. Abdel Aleem A, el Sheikh S, Mokhtar A, et al. The perineal groove and canal in males and females-a third look. Z Kinderchir 1985;40(5):303-7.
5. Sekaran P, Shawis R. Perineal groove: a rare congenital abnormality of failure of fusion of the perineal raphe and discussion of its embryological origin. Clin Anat 2009;22(7):823-5.

6. Mullassery D, Turnock R, Kokai G. Perineal groove. J Pediatr Surg 2006;41(3):e41-e43 